\title{
A Comparative Study: Expectations of Higher Education for Taiwanese Indigenous Students
}

\author{
Feng-Ying Chou \\ Doctoral candidate \\ Department of Education \\ National Taitung University \\ Taiwan
}

\begin{abstract}
This study uses stratified /cluster random sampling to explore how indigenous students across Taiwan experience different expectations with regard to receiving higher education. A survey was distributed among 1300 aboriginal senior high students in Hualien and Taitung. A total of 1,216 effective questionnaires were obtained. One-way ANOVA and a test for homogeneity of proportions were used to analyze the sample data. Research results indicate that there exists a significant difference in the expectations of higher education for indigenous students in Taiwan: the Amis and Truku (previously known as Taroko) peoples have a significantly lower expectation of students pursuing high education than do the Paiwan and Bunun tribes. It is recommended that the Amis and Truku students be placed in a remedial program to reduce the marginalization of these students in higher education.
\end{abstract}

Keywords: indigenous people(s), educational expectations, one-way ANOVA, test for homogeneity of proportions

\section{Introduction}

Taiwanese aboriginal languages have ancestral roots in Austronesian languages. These indigenous people comprise 14 ethnic groups, each of which has its own distinct language and social customs. They are the Atayal, Saisiyat, Bunun, Tsou, Amis, Pinuyumayan, Paiwan, Rukai, and Tao (previously known as Yami), and those whose tribe names were recently rectified to Thao, Kamalan, Truku, Sakizaya, and Seediq (National Academy for Educational Research, 2008). During the research period, this study collected data from these 14 tribes, although there are currently 16 indigenous communities officially recognized by the government. Discussions related to Taiwanese indigenous peoples have gained increasing attention in recent years. A principal topic in these discussions has been the significant gap (21.28\%) between aborigines and other groups in rates of bachelor's degree attainment (Chou, 2012). Education plays a vital role in choice of occupation and social status (Huang, 1990), while educational expectations convey aspirations of continued pursuit of formal educational achievement for the purposes of improved social status (Xie, Hou, \& Zhao, 2003). The vast majority of literature on Taiwanese aboriginal peoples has described the aboriginal population in a generalized fashion. However, these groups claim distinctly different ethnic identities and use different languages. The variable of indigenous ethnic group has rarely been employed by Taiwanese researchers. Exceptions include Shen (2003), who used this variable to verify that junior-high students' pursuit of higher education varies significantly among ethnic groups. Other researchers such as Li (2006), Zhuo (2002) and Lan (2006) employed the variable of indigenous ethnic group and obtained similar results. There exists some evidence that Asian Americans tend to have higher educational expectations than their white counterparts. By taking the "explanatory power" of the factors contributing to Asian Americans' higher academic expectations into account, these studies specified Asian Americans as those of Chinese, Philippine, Japanese, or Korean descent, or from Southeast Asia or South Asia. They engaged in extensive discussion over the factors contributing to parental expectations of their offspring's educational achievements. Interestingly, results showed that Asian Americans indeed held higher educational aspirations than white parents, but that they do not experience equitable social status (Goyette \& Xie, 1999). This seems contrary to a common presumption that social status is positively associated with educational expectations. However, homogenizing all Asian Americans into one group remains a major blind spot for studies in this field.When it comes to the patterns of assigning hereditary surnames to family members, allocation of rights or properties, and one's role performance within the family, different aboriginal tribes follow different practices. 
For example, the Amis are a matriarchal society, in which husbands marry into the wife's family and live with them thereafter, while daughters of a family inherit property. Patriarchal families are prevalent in the Paiwan and Rukai communities, where males dominate in all aspects of family and social domains. Within a family, the father provides supervision to boys, while the mother is responsible for taking care of daughters (Liu, 1998). In short, different indigenous communities practice various cultural practices and social customs, and develop different educational expectations for their offspring. There are no generalizations that apply to particular communities. Therefore the aim of this study was to compare differences in educational aspirations among Taiwanese indigenous peoples in order to provide the authorities with concrete, reliable data. The authorities can then use this data to start remedial programs to lend support to aboriginal students from lower-expectation contexts, so as to effectively increase the educational expectations of the entire indigenous community and ultimately bridge the higher-education gap between Taiwanese indigenous peoples and other groups in Taiwan.

\section{Methodology}

1300 questionnaires were distributed among senior-high students in Hualien and Taitung. A total of 1,251 questionnaires were returned, and 1,216 were effective. We employed one-way ANOVA to analyze differences in expectations of higher education among indigenous communities, and performed a test for homogeneity of proportions to examine how these expectations affect the academic choices of indigenous youths. For statistical optimization, this study categorizes these students into the Amis, Truku, Bunun, Paiwan, Beinan, Bunun, and other assorted groups (constituting a variety of indigenous tribes). The indicators of educational expectations are "highest level of education" and "type of school at which they choose to pursue further education". The highest level of education attained is closely associated with the length of time (in years) they spend in school, and school type is categorized into vocational and academic institutions..

\section{Results and Discussions}

\subsection{Test of differences in expected highest level of education}

Table 1 indicates a significant difference exists in the expectations of highest level of education among indigenous families using one-way ANOVA $(\mathrm{F}=8.215, \mathrm{p}<.001)$. The homogeneity of proportions test reached a significant level, affirming the heterogeneity of variances. As sample size varies in these groups, we conducted posterior comparisons using Dunnett T3. Results show that the highest level of education expected of Paiwan students is significantly higher than that expected of Amis or Truku students. Also, the highest level of education expected of Bunun students is significantly higher than that expected of their counterparts from the Truku tribe.

Table 1 Summary of variance analysis on expected highest levelof education for Taiwanese indigenous students

\begin{tabular}{|c|c|c|c|c|c|c|c|}
\hline Variable & $\begin{array}{l}\text { Ethnic } \\
\text { group }\end{array}$ & Number & Mean & $\begin{array}{l}\text { Standard } \\
\text { deviation }\end{array}$ & F-test & Significance & $\begin{array}{l}\text { Posterior } \\
\text { comparisons }\end{array}$ \\
\hline \multirow{7}{*}{$\begin{array}{l}\text { Expected } \\
\text { highestlevel } \\
\text { education }\end{array}$} & Amis & 565 & 15.69 & 2.144 & \multirow{7}{*}{8.215} & \multirow{7}{*}{$.000 * * *$} & \multirow{7}{*}{$\begin{array}{l}\text { Paiwan }>\text { Amis } \\
\text { Tribe\&Truku } \\
\text { people; } \\
\text { Bunun }>\text { Truku }\end{array}$} \\
\hline & Truku & 197 & 15.31 & 2.169 & & & \\
\hline & Bunun & 143 & 16.10 & 2.157 & & & \\
\hline & Paiwan & 126 & 16.77 & 2.169 & & & \\
\hline & Beinan & 82 & 16.06 & 2.145 & & & \\
\hline & $\begin{array}{l}\text { Other } \\
\text { assorted } \\
\text { group }\end{array}$ & 96 & 16.03 & 2.417 & & & \\
\hline & Total & 1,209 & 15.84 & 2.207 & & & \\
\hline
\end{tabular}

$* * * \mathrm{p}<.001$ 


\subsection{Variance test on choice of school type}

We performed a test for homogeneity of proportions to analyze differences among different ethnic groups in their choice of school type. Table 2 shows that a significant difference exists in the percentage of schools attended by Taiwanese indigenous students $(\chi 2=95.247, \mathrm{p}<.001)$. The percentage of Amis students admitted to private twoyear junior colleges is significantly higher (adjusted residual $=2.5>1.96$ ) than Bunun and Paiwan students (adjusted residual at| $-2.6 \mid>1.96$ simultaneously). Truku students seem to prefer private technology colleges (adjusted residual $=2.4>1.96$ ). The percentage of Amis students admitted to national technology colleges is significantly higher (adjusted residual=3.1>1.96) than Paiwan and Beinan students (adjusted residual=| $2.1 \mid>1.96$, and $|-2.0|>1.96$, respectively). The percentage of Truku students admitted to private technology universities is significantly higher than other indigenous groups (adjusted residual=2.2>1.96). The percentage of Truku students admitted to national technology universities is significantly higher than other indigenous groups (adjusted residual $=2.0>1.96$ ).

The percentage of Beinan students admitted to private comprehensive universities is significantly higher than other indigenous groups (adjusted residual=2.1>1.96). The percentage of students from the Paiwan, Beinan, and other assorted tribes admitted to national comprehensive universities (adjusted residual=3.6>1.96, 2.3>1.96, 2.2>1.96, respectively) are significantly higher than other indigenous groups, whilst the Amis students (adjusted residual $=|-3.1|>1.96$ ) and Truku students (adjusted residual $=|-3.8|>1.96$ ) are significantly lower than the average. In short, students from Paiwan, Beinan, and other assorted tribes have a significant inclination towards attending national comprehensive universities in pursuit of advanced study. The Amis and Truku students are significantly less likely to choose to attend a national comprehensive university for further study.

Table 2 Cross analysis onhomogeneity of proportion test for school type chosen for completion of advanced education

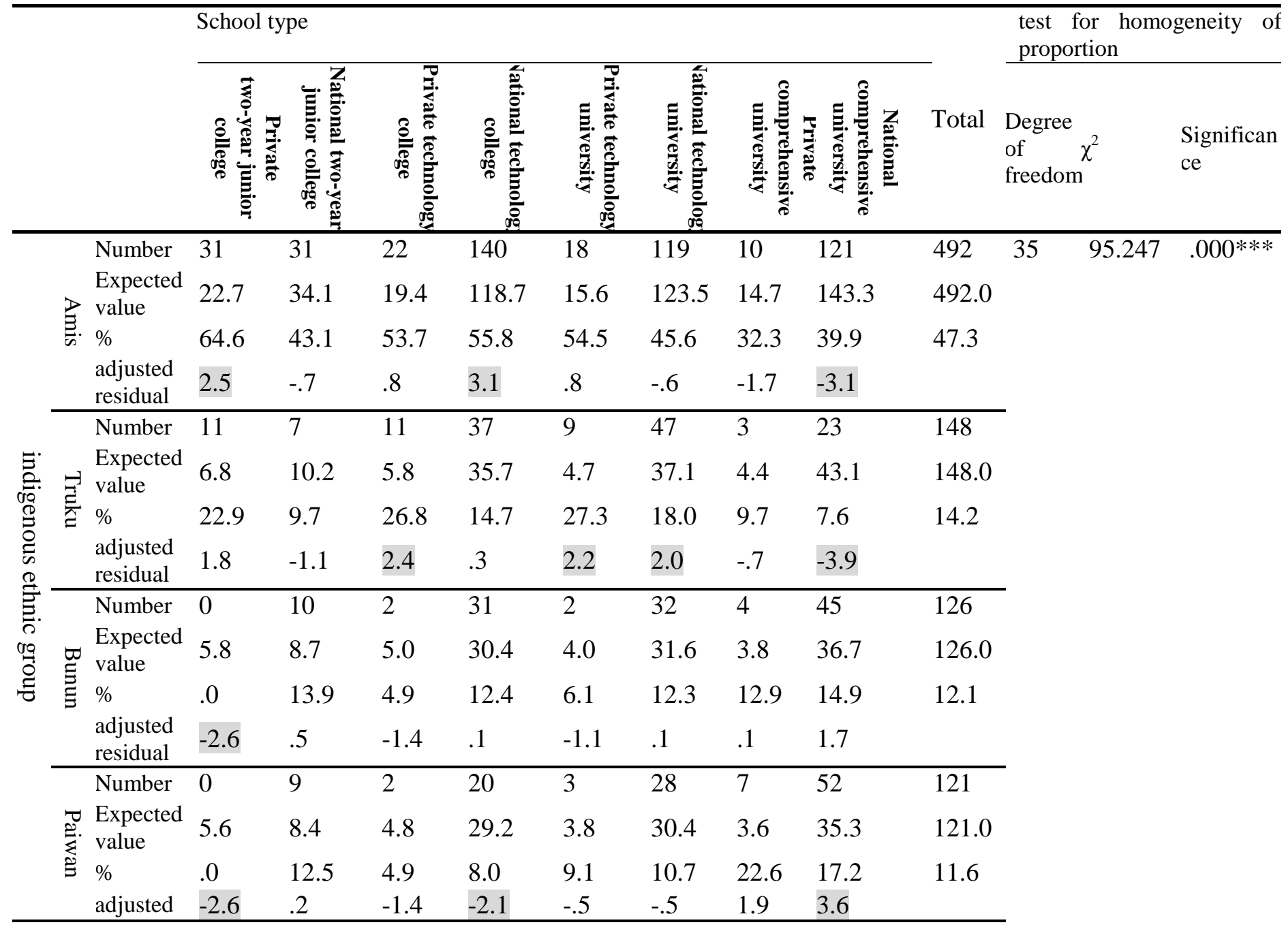




\begin{tabular}{|c|c|c|c|c|c|c|c|c|c|c|}
\hline \multirow{4}{*}{ 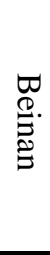 } & \multirow{4}{*}{$\begin{array}{l}\text { Number } \\
\text { Expected } \\
\text { value } \\
\% \\
\text { adjusted } \\
\text { residual } \\
\end{array}$} & 1 & 8 & 1 & 10 & 1 & 15 & 5 & 29 & 70 \\
\hline & & 3.2 & 4.8 & 2.8 & 16.9 & 2.2 & 17.6 & 2.1 & 20.4 & 70.0 \\
\hline & & 2.1 & 11.1 & 2.4 & 4.0 & 3.0 & 5.7 & 16.1 & 9.6 & 6.7 \\
\hline & & -1.3 & 1.5 & -1.1 & -2.0 & -.9 & -.7 & 2.1 & 2.3 & \\
\hline \multirow{4}{*}{ 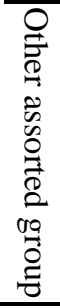 } & Number & 5 & 7 & 3 & 13 & 0 & 20 & 2 & 33 & 83 \\
\hline & $\begin{array}{l}\text { Expected } \\
\text { value }\end{array}$ & 3.8 & 5.7 & 3.3 & 20.0 & 2.6 & 20.8 & 2.5 & 24.2 & 83.0 \\
\hline & $\%$ & 10.4 & 9.7 & 7.3 & 5.2 & .0 & 7.7 & 6.5 & 10.9 & 8.0 \\
\hline & $\begin{array}{l}\text { adjusted } \\
\text { residual }\end{array}$ & .6 & .6 & -.2 & -1.9 & -1.7 & -.2 & -.3 & 2.2 & \\
\hline \multirow{3}{*}{$\stackrel{\vec{\vartheta}}{\ddot{\Theta}}$} & Number & 48 & 72 & 41 & 251 & 33 & 261 & 31 & 303 & 1,040 \\
\hline & $\begin{array}{l}\text { Expected } \\
\text { value }\end{array}$ & 48 & 72 & 41 & 251 & 33 & 261 & 31 & 303 & 1,040 \\
\hline & $\%$ & 100.0 & 100.0 & 100.0 & 100.0 & 100.0 & 100.0 & 100.0 & 100.0 & 100.0 \\
\hline
\end{tabular}

\subsection{Discussions}

With respect to expectations of highest level of education, students from the Paiwan and Bunun tribes hold high expectations, whereas the educational expectations for Amis and Truku students are significantly lower than their peers. With regard to school type, a significantly higher percentage of Amis students have chosen private two-year junior colleges or national technology colleges as opposed to national comprehensive universities. A significantly higher percentage of Truku students attend a private technology college or private/national technology university as opposed to a national comprehensive university. A significantly higher percentage of Bunun students decide not to go to a private two-year junior college, whereas a significantly higher percentage of Paiwan students decide in favor of a national comprehensive university as opposed to a private two-year junior college or national technology college. A significantly higher percentage of Beinan students are in favor of a private or national comprehensive university over a national technology college. Other assorted groups have a significant preference for national comprehensive universities.

\section{Conclusion}

This study confirms the existence of significant differences in expectations of Taiwanese indigenous students with respect to higher education. Of these groups, the Amis and Truku hold the lowest expectations of highest level of education. These groups are likely to attend a private two-year junior college, which requires less time for completion of a degree. Conversely, Paiwan and Bunun students are expected to attend the best possible schools, and a significantly higher percentage of students do not attend private two-year junior colleges.

\section{Recommendations}

This study reveals significantly lower educational expectations from the Amis and Truku communities. It has been proven than it is inaccurate to perceive all Taiwanese indigenous peoples as a homogenous group. Therefore we advise that the authorities concerned should develop research-based policies and formulate remedial programs that specifically target the Amis and Truku peoples in their efforts to render equal opportunities to higher education in Taiwan. 


\section{References}

Chou, Hui-Min (2012). Deliberating Indigenous Edu.cation from the Perspective of Educational Opportunity Equality. Taiwan Journal of Indigenous Studies, 5(3), 1-18.

Goyette, K., \&Xie, Y. (1999). Educational expectations of Asian American youths: Determinants and ethnic differences. Sociology of Education, 72(1), 22-36.

Hwang, Yih-Jyh (1990). The Inequality of Opportunities for Higher Education in Taiwan. Thoughts and Words, $28(1), 93-125$.

Lan, Tien-Hung (2006). The Study on the Vocational High School Part-Time Job Student Work Values in Taitung.Unpublished thesis. Department of Industrial Technology Education, National Kaohsiung Normal University, Kaohsiung.

Li, Cheng-Hsiu (2006). A Study on the Affecting Factors of Choosing Program for Comprehensive Aboriginal Students in Hualien and Taitung Country .Unpublished thesis.Department of Industrial Education and Technology, National Changhua University of Education, Changhua.

Liu, Rou-Lan (1998). The Characteristics and Parental Education of Indigenous Families.Student Counseling, 59, 44-49.

National Academy for Educational Research (2008). Website: http://3d.nioerar.edu.tw/2d/native/course/course_0101.asp (gleaned on Dec. 24, 2008)

Shen, Hui-Jun (2003). A Study on How Indigenous Junior High School Students in Hualien Adapt to School Education and Aspire to Higher Level of Education. Unpublished thesis.Department of Civic Education and Leadership, National Taiwan Normal University, Taipei.

Xie, Jin-Qing, Hou, Shih-Chang, \& Zhao, Jing-Wan (2003).The study of the parental educational expectation and effect factors in junior high schools. Journal of National Hsin Chu Teachers College, 16, 89-115. 